\title{
War Traumatized Adolescents (WTA): A Study on the Coping Strategies Adopted by the School Going Adolescents, Vavuniya, Sri Lanka
}

\author{
S. Hariharathamotharan ${ }^{1, *}$, Dilrukshi Abeysinghe ${ }^{2}$ \\ ${ }^{1}$ School of Social Work, National Institute of Social Development, Sri Lanka \\ ${ }^{2}$ Department of Sociology, University of Colombo, Sri Lanka
}

Copyright $\bigcirc 2016$ by authors, all rights reserved. Authors agree that this article remains permanently open access under the terms of the Creative Commons Attribution License 4.0 International License

\begin{abstract}
This study on traumatized adolescents presents the causes and consequences of psychosocial impacts of war on a select cohort of traumatized adolescents. It initially contextualizes the problem by narrating the physical and psychological impacts of war on people. The sample of school going adolescents was selected from the Southern Educational Zone of Vavuniya in northern Sri Lanka, an area predominantly occupied by Sri Lankan Tamils. The relevant information on those traumatized adolescents was obtained from medical practitioners, school teachers and others who had worked with the said traumatized adolescents. A survey was conducted thereafter to obtain the required qualitative data. In many instances semi-structured interviews were held to elicit additional information. The coping strategies adopted by the said school children were then analyzed using the BASIC-Ph multi-dimensional approach, based on the multi-modal therapy (Lahad, 1992). In this study, the conceptualization of coping is based on a proposal by Lahad and his colleagues in which coping is viewed as a response to perceived stress which was defined as "constantly changing cognitive and behavioral efforts to manage specific external and/or internal demands that are appraised as taxing or exceeding the resources of a person". Findings of the research revealed that the selected samples of adolescents were least resilient to severe impacts of war and that their coping mechanisms varied due to varying factors such as their personality, social support, and spirituality. Overall, it may be said that nearly all of them showed symptoms of having been traumatized at different levels, with many of them needing psychosocial support.
\end{abstract}

Keywords Trauma, Adolescents, Coping Strategies

\section{Contextual Background}

The protracted ethnic conflict in Sri Lanka that lasted for more than three decades took its toll on all groups of the population particularly in the northern and eastern provinces of the country[1-3]. The skirmishes between the warring factions made the people flee for their lives multiple times leading to multiple displacements and the people lived in fear and uncertainty ever ready to run with their meager personal belongings.

The conflict took place in several spells causing considerable loss of life, physical injuries and adverse traumatic impacts especially among the school going population [4-6].These impacts also affected their economic activities by forcing them to flee to other local and international destinations. Among the different age groups of the population the school going children in the Northern Province of Sri Lanka were among the most affected, psychosocially[3].

This study chose to undertake a closer look at the impact of the war, particularly the psychological impacts of the war on the school-going population for several reasons including the academic interest of the authors, easy access to the study area which enabled the research team to check on the veracity of the available information on the school going adolescents falling within the age group of 10 to 19 years.

Among the impacts of war the invisible impacts affecting the mental health of victims remains a least studied \& researched area[1]. The young and the weak, particularly the school-going children, accounted for a considerable percentage among the victims of severe mental health. They were reported to have suffered and endured the most number of traumatic events, while some had attempted to cope with, often unsuccessfully. Published literature on such phenomena is limited to a few research studies conducted by eminent medical personnel like Somasundaram[7].

The general consensus of opinion on the impact of calamitous events such as war on people was that the young endure the impact better and that they are more resilient. However, in reality it has been found that the children are very much less resilient and are less prepared to cope with 
and therefore display less effective coping skills. This study therefore concentrated on this aspect for detailed study. The study uses select sample of war traumatized school-going adolescents from the district of Vavuniya in North Sri Lanka. Such a study, it is hoped, will fill the gap/lacuna apparent in the research on the subject area. Furthermore this study is also expected to come up with additional empirical evidence for the professional social workers and psychiatric social workers in practice and the policy makers engaged in formulating policy initiatives on this area.

\section{Stress and Coping}

This study is based on the theory of psychological stress and coping developed by Lahad(1992) and his colleagues over a number of years [8-10]. This useful new approach assumes the existence of coping resources,(both active and/or dormant), in every individual. These interdependent resources, identified through observation and exploration of traumatized populations [11] were grouped into an integrated group called: BASIC-Ph, comprising of characteristics such as: Belief, Affect, Social interaction, Imagination, Cognition and Physiology. The BASIC-Ph multi-dimensional approach, inspired by the ideas of multi-modal therapy [12], relates to six dimensions of coping. It suggests that each individual's coping style comprises of an idiosyncratic combination of six dimensions, which act as input and output channels in a person.

Everyone has the potential to use all six channels for coping. Children, like adults, respond to traumatic stress in more than one of the channels given below;

The spiritual channel (B) sustains religious attitudes, value systems, and the search for sense.

The affective channel (A) processes the broad range of emotions activated by the trauma and their verbal or non-verbal appearance.

The social channel (S) has group belonging, role fulfillment and the mutual function of receiving and giving support.

The imaginative channel (I) enables the amelioration of stress by denial and fantasy, but is also responsible for the original solutions to the problems by imagery, dreams and intuitions.

The cognitive channel (C) displays strategies as well as information gathering, problem solving and positive thinking.

The physical channel $(\mathrm{Ph})$ is broadly responsible for the Negro-chemical changes and motor reactions to stress, as well as behavioral ways of management stress that may range from rest to excessive physical activity [11].

\section{Methodology}

The methodology adopted was qualitative. The study area selected was the Southern Zonal Education region of the Vavuniya District in Sri Lanka. The sample of school going adolescents selected by the counselors and doctors who treated them was purposive and the snow balling technique was used to reach the numbers required. The sources used for such information were the focus groups, in-depth interviews and semi structured interviews.

Table 1. Distribution of Samples by Sources of Data/Sex

\begin{tabular}{|c|c|c|c|}
\hline Sources of Data & Male & Female & Distribution \\
\hline \multicolumn{4}{|c|}{ Semi-Structured Interview } \\
\hline $\begin{array}{c}\text { Traumatized } \\
\text { School Children }\end{array}$ & 3 & 3 & Mean(12.83),SD(1.47) \\
\hline School Teachers & 3 & 3 & $\operatorname{Mean}(46), \operatorname{SD}(7.12)$ \\
\hline $\begin{array}{l}\text { Priest and Temple } \\
\text { head }\end{array}$ & 3 & 3 & $\operatorname{Mean}(41.5), \operatorname{SD}(4.1)$ \\
\hline $\begin{array}{l}\text { Psychiatric Social } \\
\text { Workers }\end{array}$ & 2 & 2 & Mean(41), SD(3.7) \\
\hline \multicolumn{4}{|c|}{ Focus Group Discussion(6) } \\
\hline $\begin{array}{c}\text { Traumatized } \\
\text { School } \\
\text { Children(2) }\end{array}$ & 10 & 12 & Mean(13.5), SD(1.8) \\
\hline $\begin{array}{c}\text { School } \\
\text { Teachers }(2)\end{array}$ & 8 & 7 & $\operatorname{Mean}(39.8), \operatorname{SD}(6.2)$ \\
\hline Parents(2) & 11 & 10 & Mean(44.1), SD(5.0) \\
\hline \multicolumn{4}{|c|}{ Narratives(6) } \\
\hline $\begin{array}{c}\text { Traumatized } \\
\text { Children selected }\end{array}$ & 3 & 3 & Mean(13.1), SD(1.7) \\
\hline
\end{tabular}

\section{Research Tool}

Data were collected from individuals who experienced the phenomenon. Data collection in phenomenological studies often, consists of in-depth interviews and multiple interviews with participants [13]. In this study, to generate primary data from the participants, three data collection tools, such as, in-depth interview schedule, semi-structured interview schedule and the interview guidelines (FGD participants) were used as key methods. These instruments were used as a reflective-report to obtain the experiences and perceptions of participants from a general spectrum with an in-depth view with regards to their experiences.

\section{Data Collection}

Qualitative data was gathered for this research by conducting semi-structured interviews, focus group discussions and narratives on experiences adopted to cope. Semi structured interviews were undertaken with the selected school going adolescents such as teachers, counselors, social workers, probation officers and other service providers.

Ten focus group discussions (FGD) were subsequently conducted selecting two from each group consisting of care givers and other respondents. The FGDs were conducted in diverse settings using primary language of each group, these FGDs were held in the classrooms of two schools in each district. The FGDs included on the average twelve participants (Range 6-12) and adolescents within the age range of 10 to 18 years.

The narratives were recorded from selected war traumatized adolescents with additional narratives included from the respective adolescent's their relatives and 
caregivers. The reason for using this methodology is to gain an in-depth understanding of the situation. The qualitative aspect gives a clear insight into the coping strategies adopted by the children and to ameliorate their direct experiences. To confirm the validity of the results obtained from the data collected from traumatized adolescents through semi-structured interviews they were triangulated with the results of the focus group discussions and key informant interviews.

\section{Data Analysis}

As the focus of this study was on traumatized school going population this study had attempted to resolve their immediate problems by carrying out a critical study of the coping strategies by using BASIC-Ph multi-dimensional approach. The textural/structural data analysis technique was used to process and analyze the textural information. The entire sets of descriptive data used in the textural/structural data analysis were verbal statements obtained from the respondents. The very words used by the respondents were used. When using this technique imaginative variations too were experimented. Some words or sentences obtained from the verbal interview, focus group discussions and narrative interviews data were highlighted to emphasize their significance.

\section{Analysis of Findings}

\section{Coping Strategies}

This study revealed that most of the recent cases of war affected in the district of Vavuniya were the victims of claymore blasts, aerial bombing, gunfire and shelling. The study revealed that the symptoms of traumatic experiences of war among the selected sample of school going adolescents, both boys and girls, were in the form of aggressive and rash behavior, expressions of feelings of insecurity, emotional outbursts/ throwing tantrums, addiction to alcohol/smoking, showing least respect to parents/teachers \& adopting coping mechanisms that were largely amateurish.

As a result the war traumatized children were found to have lost interest in studies, refusing to attend school, becoming listless, losing their drive or interest in life and having problems with relationships. In addition, [6-7] it was found that besides displacement other factors like unbearable experiences of leaving their homes and belongings, parting from their pets, school, plants or trees, being forced into a new environment, new surroundings and new schools and painful experiences witnessing their parents die, have also impacted severely on the victims.

This study also found that the majority of the war affected adolescents seemed to have coped with severe distresses caused by traumatic experiences. Coping strategies were widely individualistic. Some strategies were found to be positive while others seemed to have caused further complications. It was also discovered that some of the adolescents had negative coping strategies leading to inappropriate behavior like physical, reactions resulting in hitting class mates blaming self, addiction to alcohol/smoking and harassing others, which had caused negative consequences. The characteristics of the coping strategies of trauma affected war victims particularly among the young and the inexperienced had been too amateurish resulting in unwanted consequences.

\section{Theoretical Underpinnings of Coping Strategies}

In the Basic $\mathrm{Ph}$ model the first most predominant objective deals with six potential channels or relationships. Within this theme, three sub themes were identifiable and they were family relationships, school relationships and community relationships. Within the subcategory of family relationships, the importance of cultivating strong family ties was emphasized. These themes when depicted diagrammatically revealed very clearly the factors that contribute to the formation of those themes by either promoting or impeding development (see diagram given below).

There is also no clear consensus as to which coping strategies or modes of coping were most useful, and how well coping strategies resolved problems, prevented future difficulties, or relieved emotional distress. The few studies that have examined the relation of coping to some outcome measure have also produced inconsistent results. For example, some studies have found that problem-focused coping decreases emotional distress, while emotion-focused coping (paradoxically) increases [14-16]. Others, however, have reported the opposite pattern [17]. 


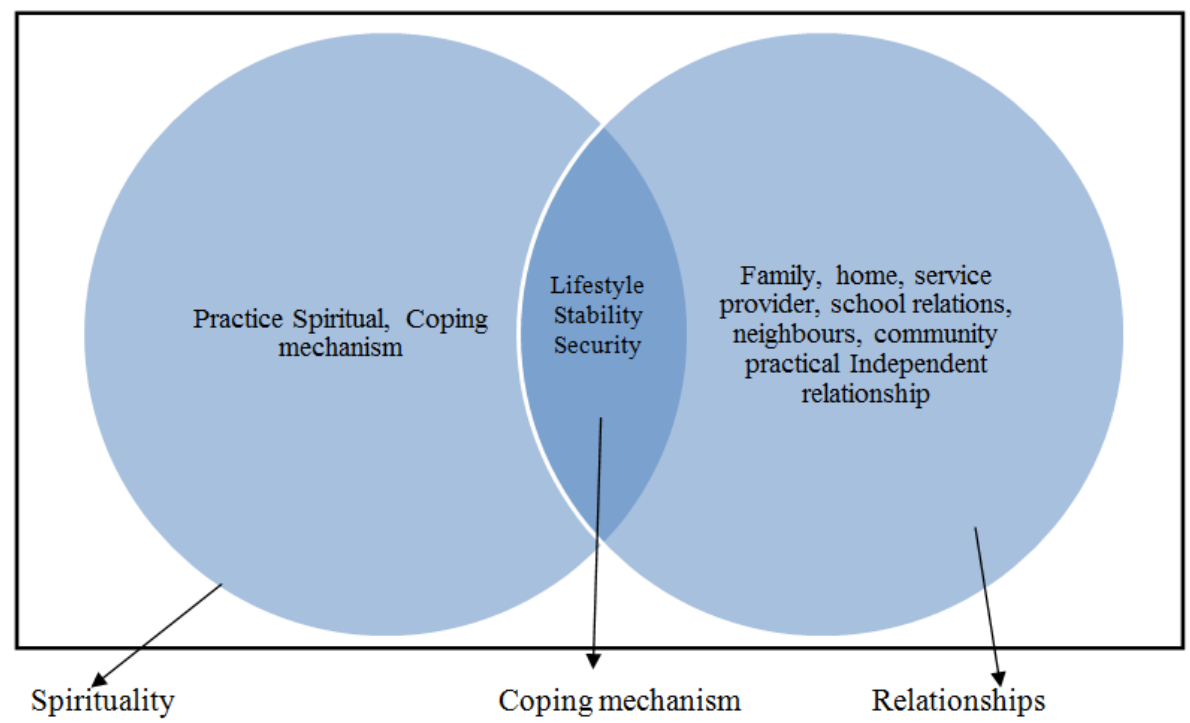

Figure 1. Coping Based on Basic Ph model depicted in a Venn diagram

The two predominant sub themes, as shown in the diagram are relationships and spirituality. From these themes, sub themes emerge dealing with practical co-dependent relationships, spiritual coping mechanisms and spiritual relationships. Within the core themes and sub themes, issues pertaining to lifestyle, stability and security were constructed. Each theme and sub theme is interpreted below highlighting their relevance to the present study.

\section{Relationships}

Within relationships that are used for coping, the qualitatively derived outcomes revealed the co-dependent relationships as a predominant theme contributing to survival both on a daily basis as well as when confronted with adversity. These relationships identifiable across all systems in the ecological environment were observable in the results of the interviews, underscoring the necessity for co-dependent relationships to exist within the Sri Lankan Tamil culture. Co-dependent relationships were discussed as critical in terms of child rearing, education, work. Community services and religious relationships, irrespective of age, family, or work status.

The first most predominant objective deals with relationships. Within this theme, three sub themes were distinguishable. These sub themes are family relationships, school relationships and community relationships. Within the subcategory of family relationships, the participants discussed the importance of cultivating strong family ties.

One of the Counselors (38 years, female) stated that, "Some of the children were always engrossed with their problems but the parents did not understand the children's concerns as the parents did not keep track of the children's activities. The family had no resource to find out the problems of their children, and they are left in a vacuum" The Counselor continuing on the subject stated that. "The child must feel free to approach the parents when they are embroiled in a problem. Furthermore the counselor stated that overall the children must feel secure and wanted in their homes. Some parents were found to be too indulgent which did not help to resolve the problems that children faced. Participating in all the activities of the children goes a long way to give that security to the children. Another Counselor (45 years, Female teacher) while talking about her experiences told that she has come across children affected by violence in the family between their parents. Such events should be avoided by the parents as it leaves indelible marks in their minds of the children. Many parents do not know this aspect as they are supposed to have stated that such problems are important. Both Counselors were also of the opinion that it is important for children to be obedient their parents. A mother of a 12 year old child discussed relationships with extended families including "brothers, sisters, parents, grandparents, cousins, uncles, aunts, in-laws and at times domestic helpers"......We were taken good care of at our husband's sister's house with special meals consisting of raw country rice, chicken curry, eggs from country hens and milk"...... "My mother took special care of me and my daughter. Though transport was a problem we managed to get our wounds cleaned and dressed by a hospital attendant living close to our home. We took grater interest in attending to the most wounded one who started to come round and begin her studies.

In the school premises, a 12 year old girl's mother discussed how she felt the critical need to foster a trustful, secure relationship with the children. "On the 26th of June 2009 my husband went farming as usual. Even after night fall my husband and his four friends who went along with him, had not returned due to being arrested by the army. The problems started with my husband missing "when my daughter started going to Vavuniya convent girls' high school for her primary education she noticed parents bringing their children to school and back home by vehicles When I take my child to school her routine question was "why doesn't my father bring me to school like the fathers of 
other children "where is he Amma". Why do you bring me?" she cries as she asks these questions.....then "On the way to school whenever she saw children going with their parents she would stop on the road and cry "I want my father". Some school children had told her that she could get her father back if we paid one hundred thousand rupees to the army." Thereafter, she told her classmates "please tell my mother to pay the required sum of money and have my father released" she came home and quarreled with me.

A 38 year old female Counselor stating 'an example of a child coming with his parents reiterated that, the parents must be educated to resolve problems related to the situations of developing inferiority complexes. The problem was that he was not respected in the class. The teacher was also biased for the child to develop such a complex. On observing this situation we talk to the child first then later to the teacher which eventually help the child to get back to school happily.

Some children came to school clumsily dressed and engaged in undesirable activities said a 45 years female teacher counselor and continued to say that, "I give special attention to children who are inattentive or behave as disturbing elements in the class room"...I have frequent personal dialogues with children, who have problems. It is practically impossible to find out their real problems at the first meeting. It takes some time and I have to meet the friends, siblings and if necessary the relative of the child concerned, so as to identify the problems. Some children resort to disgusting behavior, they are branded as naughty children. In fact their family problem remains in the back of their mind including, their family background, and their environment they live in. A 13 year old boy's mother discussed that one day she participated in the school sports meet then........the children who won the race were given certificates. But he became sad because his friend got a certificate while he could not get one, His father had told her that he will buy him a certificate from the shop and there will be sports meet next year too. So his sadness disappeared. "The school gave prizes to all those who participated He too got a prize so he was happy and accepted it" In order to encourage these relationships child positive reinforcement given to school activities and discipline, is important and trying to understand each child's temperament in order to capitalize on their full potential becomes necessary One of the Psychiatric Social Worker explained that, "it was also pertinent to foster open, communicative relationships with the children's parents, discussing such Issues as changes and problems in family structure, extracurricular activities etc". By having an Open Dialogue with the parents the children felt that the children would have continuity in their environments in terms of stability and safety.

The community/Neighbors relationships also emerged as an important factor with all participants. The informants believed that raising children in a community atmosphere was very important, with relationships within the community including parents, extended family. Teachers, siblings, and religious affiliations. During the Focus group discussion with Traumatized Adolescents parents "one must rely on these relationships to survive on a daily basis." Community/Neighbors relationships were highlighted in different ways throughout the discussions. "When we look at the families of today we all are nuclear families. When there is a problem to save their own family is the concern. Therefore, it has become a problem. During the wartime we lived jointly together as a group. This gave a sense of security to the children. When they have a religious ceremony or a prayer meeting as a group. "We think that the environment is also important to the child. If the people around are not good the child will learn bad habits from them. Therefore the neighboring people will influence the child"....... Sometimes the neighbors instigate the child to behave in a bad way. If a girl and boy talk in friendly terms about their lessons they are branded as a couple leading to unwanted social problems, As far as we know we have been looking in to certain problems, we find that the neighbors had a role to play in the child's problem "Community relationships were established through her work at her children's school in which she helped with counseling duty well general school work. The children of the trauma receive support by the community, through NGOs and social support by volunteers.

The observational data, also revealed that, within the ecologically stable environments the participants tended to engage in more co-dependent activities as compared to their counterparts in ecologically unstable environments, which tended to be more isolated socially. These findings corroborate with past research, wherein reciprocity and interactive relationships are defined as factors that support successful coping in various living conditions, providing opportunities for individual growth, with family and community cohesion [18].

The second sub- theme dealt with spiritual relationships, wherein spirituality was discussed as an important aspect of the interpersonal relationships that existed within the Sri Lankan Tamil culture. The spiritual relationships were established between the service providers and the children, between the children, and within the home, school and community environments. This form of relationship was not observed among the traumatized adolescents. As these relationships existed only within the groups of children who were well adjusted, it could be construed to mean that these relationships contributed to the stabilizing of their ecologic systems, potentially mitigating the effects of exposure to war trauma and promoting healthy development.

These findings seemed to corroborate with the findings in some of the literature dealing with practices in Hinduism/ Christianity etc. These findings also indicated that such practice within a spiritual community is essential to help facilitate an individual's spiritual growth and development. In contrast, spiritual isolation is reported to be hindering such development. As the practice of religions deals with developing deep and close friendships with others, the inability to practice such religion due to one's living and 
working environment can produce difficulties in being able to change and grow [19].

\section{Spirituality}

The second sub theme that emerged dealt with spirituality as a means of coping with daily events as well as with the ongoing internal conflict. Most of the informants discussed the value of their spiritual practice as a strength that allowed them to help others and themselves, stressing that through prayers and meditation they gain protection and courage to survive. These findings too supported by past literature [17-19] dealt with the underlying principles of the religious practice, in which protection is gained through regular practice of meditation [19].

The predominant objective that emerged with all informants dealt with spirituality. All informants, with the exception of Rev Father (51 years, Male), stated their beliefs regarding Christianity. Another Female Hindu temple priest stated more generally about a sense of spirituality rather than a concrete organized philosophy. Within this theme, several elements were identified. These elements included spirituality in the school environment and home environment. As a form of discipline, as a practice and as a coping mechanism. When all groups other than those in the home were observed, the practice of Hinduism and Christianity within the schools was reported to be pivotal. Within the schools, daily lessons were conducted about their own religions, in conjunction with daily meditations, prayer practices and adherence to Hindu and Christian precepts. The children not only studied this spiritual practice formally, but were encouraged to practice it in their lives. For example, Rev Father (51 years, Male) explained about the importance of his service to needy children in schools. He felt that this act of kindness was "good for those in Christian and Hindu school" as they would be practicing what they had learnt. Another Mother of 12 years old child told that...." She started praying that the child who was ill should develop keenness in studies after which the children started do her day-to-day activities gradually. She was going to school and we started to give normal diets. My mother had taken a vow that she would give a handmade of silver to the Vavuniya Amman temple.

The following year in the month of August, we went to the temple to fulfill our vows". The mother of a14 year old boy explained that, "some of our neighbors who had become converts to the Calvary church spoke to the Church Missionaries about our family conditions and plight". As a result, some of the church people came to us and talked, they said that if we had no objections they could come to our house every day and pray on our behalf. I did not object, so they came and did prayers on our behalf. My son joined in the prayers they said that "God would bless with good times". For the next month and a half, two of them came and prayed for us. At the end of the prayers every day they spent a few minutes speaking to us and trying to comfort us. Subsequently they requested us to come to church every Sunday. My son came with me to the church on two or three occasions and then accepted to saying that he was interested. The mother explained that, many people said that some evil spirit had taken on him, we sought the help of our Pastor. He came to our house every day and said special prayers for our sake. Our son used to ask us, what exactly is meant by good spirit and evil spirit. We said that evil spirit is dirty and good spirit is god's Holy Spirit. How much he understood, we really don't know. After about a month a visible change was observable in him.

Traditional healing and cultural practices are often central to people's lives in conflict affected communities in Sri Lanka[20] For example: they go to the temple festivals or engage in silent prayer, take vows to the local gods, under take fire walking, offer milk rice, undertake "Kavadi" and consulting Oracles "vakuucholluthal"

In conjunction with the practice of Hinduism/Christianity within the schools the importance of conducting these practices at home were also emphasized. The informants also reported that it was "important to provide an environment where prayers and meditation could be practiced so that the children would imbibe good religious ways." They also believed that it was important to start the children young with these religious practices.

Rev Father, Hindu temple priest and other children's mothers and fathers reported that meditating in the home twice daily is important. Hindu adolescents' parents reported that they were meditating with their family, including, their mother and their grandparents. They both reported meditating, not because they are forced to do so but because they wanted to lead a simple and good life. Another Christian Rev father (60 years, Male) reported that he communicated with the parents of students and ensures that their spiritual practices are also carried over to the home environment to encourage "a good and simple".

When spirituality was discussed in Focus group discussion with parents, they stated that through spiritual practice, children learnt to live a good life as the spiritual practices it offered the children a sense of guidance. A mother 38 years participating in the FGD discussion state that her children were always provided with an environment where prayer and meditation was regarded as important factors. She felt that "it is important to teach children from an early age in the homes how to lead a good life, a simple life where material things are not important and where not harming and was very important"

The last element that emerged was spirituality as a coping mechanism. According to Maya, Jeyaseelan, Menaka and Rajani who were participant in a FGD discussion, meditation should be practiced in order to protect oneself and others. For example, Rajani was told by her mother to meditate for her friend who had suffered tremendous loss due to the war. She was told to meditate in order to protect her friend through her difficult period. Jeyaseelan and Menaka were also told to meditate to deal with the worry of harm coming to the family. This notion was summarized by Jeyaseelan, when he stated "you must pray to be safe and to save yourselves ...you always ask to be protected and I always say that we can only 
depend on the divine help more than any other help. We have to pray. I always prayed for courage to face life. I don't think, I could have managed without that. I am always very conscious of prayers. I'm conscious of that help ... conscious of that prayer.

The third most predominant theme that dealt with spirituality was discussed by all informants. They underscored the importance of spiritual practice in their daily lives, with the exception of adolescents. Although, each respondent reported mixed religious background, adherence to particular religious practice was not observed, with the children and the parents choosing the same religion and praying, meditating, and observing the precepts once or twice a day. As the school going children were either Hindu or Christians, prayers as a daily practice was emphasized as being essential, as it was thought to provide the children with guidance and protection, encouraging good lifestyles. Literature addressing the psychotherapeutic effects of Hinduism/and Christianity, also revealed that the practice of spiritual philosophy entails a great deal of psychological satisfaction among the practitioners. Through the practice of meditation the mind is said to be removed from worry, anxiety, fear, greed, hatred, delusion and other feelings that promote unhealthy development, and directed towards promoting feelings of compassion, tranquility, joyfulness and charity[19].

Although the purpose of practicing Hinduism/Christianity is said to be mainly to attain higher levels of consciousness, it appears, as widely documented in literature, to function as a prophylactic for stress as well. In studies dealing with problems such as addiction or meditation has also shown that piety also could be an effective treatment. It is believed that through meditation individuals can become more relaxed by releasing energy to cope with the demands of life. In conjunction with this, the meditative state is thought to be beneficial for the resolution of conflicts, as it allows for a deepening of awareness [17-19]. As stated in the literature on Hindu practice, it may be assumed that spirituality related practices within the comparison group and the groups of orphans may help to bring stability within the children's environments.

Due to these benefits derived from the practice of Hinduism/Christianity it is possible that the children gain guidance and psychological protection on both a daily basis and in the event of adversity. As the traumatized adolescents were observed, to be not participating in any religious practices the protective effects of a spiritual practice may not have been existent, thus making them less capable and confident of coping with daily emerging adversities. In addition to these findings, past literature on the prevalence of resilience in children reveal that, in combination with other factors, rule setting by adults can function as a protective factor for children when faced with adversity [14]. The function of spiritual practice may thus act to promote ecological stability for these children and also potentially mitigating the effects of war and promoting healthy development.

\section{Lifestyle, Stability \& Security}

Another sub objective that emerged from the interviews was that of trying to live a good Lifestyle. According to all the participants, a good and simple lifestyle should be strived for knowing that hard work is important while material things are not. One helps the others survive by willing to help. According to the adult informants this teaching comes from the fact that one has to be raised by a family in a community, which includes family, school, religion and social structure. In the last sub objective that emerged, issues of stability were discussed similar to security. The means for establishing stability was stated by the informants as occurring through co-dependence and creating a sense of community, religion, family school and social structure and by leading a good, simple life.

Instability was mainly discussed in terms of social structure at the Focus Group Discussion with Teachers wherein they discussed that effects the war on people's minds. One participant said that "this country is no good because the army, navy, police air force joint to gather in their fight" (creating war). She felt that LTTE was making us look bad to justify killing the poor villagers and children. She said that she was frightened two years ago when a bomb exploded in a bank killing the school children in Vavuniya .Another teacher stated that "the people who had been tortured have gone through a great deal, mentally, physically, financially. Violence is escalating, people are increasingly killed. Maybe when you think of history there have been wars all the time, the neighboring countries are always wanting to conquer-this shows that man has been behaving badly. She felt that "the people creating these problems have gone beyond the normal way of being divine. Their minds are not balanced ... They have really gone beyond the normal way of being divine by allowing evil thoughts to coming to their minds. People who have been living happily with all different nationalities are suddenly fighting with each other." She compares this to the present situations, fearing now that "the world is going down. down." Rajani fears that children are not being taken care of now as well as they were in the past. She feels that because of all the stress, living with war creates the need for communication both at home and at school.

In general, the results of the qualitative analysis with the various participants revealed several emergent patterns. It can be concluded that, within each environment studied. With the exception of the refugee camps, a lifestyle in which spirituality, co-dependence and strong familial and community relationships are asserted. Unlike in communities where a sense of individuality is of primary importance. The informants reveal a social phenomenon where individuals and their aspirations are not so easily demarcated. Instead, within this society, a unified effort appears to be made, with people striving for a good, simple lifestyle, where reciprocity is highly valued.

The third sub theme that emerged dealt with security. This theme emerged as a continuum, with the informants 
discussing factors that made them feel secure, as well as facts that made them feel insecure. Within the security theme, living arrangements, practical and spiritual security were discussed. The house was surrounded by relatives with aunts, uncles and cousins living across and down the street. These relatives visited daily bringing food and seeing how everyone was keeping. During the evenings, each family cooked a dish of food and would distribute it to the neighbors. By the end of the food distribution, everyone had a complete meal that was composed of the different dishes prepared by the extended family. A sense of security was established with all the informants in a practical sense by the types of relationships that were established with the knowledge that because of these relationships. Their needs are met. For example, One school teacher(37years, Male) stated that "knowing that people would come forward to help with raising the children, doing the housework as well as knowing that the children were never left alone with a baby-sitter or domestic help but always had aunts, uncles, grandparents, parent nearby to help ensured the children's security. Security was established through the belief systems in which a blend of spirituality and practicality appeared with the merging of both, wherein all the informants had the core belief system of co-dependency, communication, and sense of belonging and responsibility within a community.

In the diagram the center depicts the emergence of the two fields of spirituality and relationships in the overlap region/area leading to the emergence of the sub themes namely conglomerates of lifestyle, stability and security. This phenomenon did not emerge at the final stages of the discussions as anticipated. A closer examination of the possible causes revealed that these core themes develop as a result of the combinations of themes and sub themes previously discussed. In order to understand the core concepts those processes should be examined in totality as a part of a process of the interaction between the overarching variables outlined in the diagram.

From the interviews and focus group discussions, it was possible to observe that the informants discussed the importance of living a good simple life. This type of lifestyle was defined by religious practice, co-dependent relationships and active involvement with others, whether it is for teaching, helping, or simply fostering relationships. The informant's all spoke of the importance of not placing value on material things, but to live a life of simplicity. From these discussions, it can be seen that the various aspects of relationships and spirituality are drawn upon in order to cultivate a good life. Stability and security are also achieved, with all factors interacting. Past literature [21] has stated that there is no single thread that holds a strong family together, but rather a web of personal and social resources, where protective factors cause interactions between both individuals and their environments. Through these interactions, a forum for healthy development can emerge [21].

The results of this study provide support, with evidence for children who were well adjusted to development due to their good family background, rich in social cohesion and stability, while their less well-adjusted counterparts were found to reside in ecologically unstable environments. It could therefore be said that ecological stability is formed through an interactive process between certain relevant variables and their byproducts. As evidenced in past literature [17-19], these results reflect the notion that healthy development is a process that occurs between people and their environments which must be examined holistically in order to comprehend the situation.

\section{Conclusions}

Overall it may be said that, this study using empirical data, has demonstrated that the war traumatized adolescents displayed least resilience at different levels when withstanding the devastating impact of war. Most coped with the stress/trauma fairly adequately, sometimes with periodic relapses to create a new life with varying levels of personal and interpersonal change. Others showed alterations in personality, level of functioning and interpersonal relations and some seemed unable to re-organize and re-stabilize their lives.

Normalizing the environment after a crisis seems important for the survivors. In this regard the traditional methods of coping, with family and community support, if intact and available, retaining its natural capacity to support their members and solve problems/ difficulties of people, would be the best alternative and/or remedy.

Drawing from the results of the present study, it may be concluded that the effects of war, regardless of the duration, frequency and intensity, may be mitigated by stable ecological environments. Creating and/or improving a socially cohesive environment were found to be a vital necessity to rehabilitate the war traumatized adolescents. It also recommends that the service providers too should be professionally trained personnel, like doctors specialized in psychiatry/mental health, social workers, counselors, probation and child care officers, child right promotion officers, teachers and other professionals. These personnel should work together to form a network to enhance the quality of service provision in order to help the unfortunate victims of war to be integrated back into society and thereby contribute to social development in Sri Lanka.

\section{REFERENCES}

[1] Somasundaram D. Recent disasters in Sri Lanka: lessons learned, Psychiatry Clinics of North America. 2013; 36(3): 321-328.

[2] Tol W A, Komproe I H, Jordans M J, Vallipuram A, Sipsma H, Sivayokan S, et al. Outcomes and moderators of a preventative school-based mental health intervention for children affected by the war in Sri Lanka: a cluster randomized trial, World Psychiatry. 2012; 11(2):114-122. 
[3] Somasundaram D, \& Sivayokan S. Rebuilding community resilience in a post-war context: developing insight and recommendations-a qualitative study in Northern Sri Lanka. International Journal of Mental Health Systems.2013;7(1),

[4] Jevana S, \& Ashvine S. Post-Conflict Sri Lanka: The Lack of Mental Health Research and Resources among Affected Populations, International Journal of Humanities and Social Science.2014; 4(3):151-156.

[5] Fernando G A, Miller K E, \& Berger D E. Growing pains: the impact of disaster-related and daily Stressors on the psychological and psychosocial functioning of youth in Sri Lanka, Child Development. 2010; 81(4):1192-1210.

[6] Somasundaram D J. War trauma and psychosocial problems: patient attendees in Jaffna, International Medical Journal. 2001; 8(1): 193-197.

[7] Somasundaram D J. The tragedy of war. World Psychiatry. 2006; 5(1):36-38.

[8] Lahad M. Post Traumatic Responses in Disasters: A Community Perspective, in Gow, K. \& Paton, D. (Eds.) Resilience: The Phoenix of Natural Disasters. New York: Nova Science Publishers .2008:33-46.

[9] Rosenfeld LB, Lahad M, \& Cohen A. Disaster, trauma, and children's resilience: A community response perspective. In J. M. Richman \& M. W. Fraser (Eds.), Children, families and disasters: A risk and resiliency perspective, Westport, CT: Greenwood Press.2001:133-185.

[10] Shacham M, \& Lahad M. Stress Reactions and Coping Resources Mobilized by Children under Shelling and Evacuation, The Australasian Journal of Disaster and Trauma Studies. 2004; 2(1).

[11] Lahad M. The story as a guide to metaphoric processes. in S. Jennings (ed) Drama therapy theory and practice, Rutledge: London. 1997; 3(1): 31-42.
[12] Lahad M. BASIC Ph: The story of coping resources, In S. Jennings (Ed) Drama therapy Theory and Practice, London: Jessica Kingsley Publishers. 1992; 2(1): 150-163.

[13] Creswell J W. (Ed). Qualitative inquiry and research design: Choosing among five traditions. (2nd ed) Thousand Oaks: Sage Publications. 2007.

[14] Herrenkohl E C, Herrenkohl R C, \&Egolf B. Resilient early school-age children from maltreating homes: Outcomes in late adolescence. American Journal of Orthopsychiatry, 1994; 64(1): 301-309.

[15] Felton B J, \& Revenson TA .Coping with chronic illness: A study of illness controllability and the influence of coping strategies on psychological adjustment. Journal of Consulting and Clinical Psychology, 1984; 52(1): 343-353.

[16] Mitchell RE, Cronkite RC, \& Moos R H. Stress, coping and depression among Married couples. Journal of Abnormal Psychology, 1983; 92(1): 433- 448.

[17] Mitchell R E, \& Hodson C A, Coping with domestic violence: Social support and Psychological health among battered women. American Journal of Community Psychology.1983; 11: 629- 654 .

[18] Baum A, Fleming R E, \& Singer J E. Coping with technological disaster. Journal of Social issues, 1983; 39(1); 117-138.

[19] Vendra J L. The community context of child abuse and neglect.in Families in Community setting: interdisciplinary perspectives .S.A: Haworth Press.1990.

[20] Galappatti A. 'What is a Psychosocial Intervention? Mapping the Field in Sri Lanka', Intervention, 2003; 1(2), 3 - 17.

[21] Lahad M, \& Ben Nesher U. From Improvising in Response to Trauma to Developing a Theory: Communities Cope with Terrorism - Preparation, Intervention and 21Rehabilitation. 2 008 . 